\title{
Using ocean quahog (Arctica islandica) shells to reconstruct palaeoenvironment in Öresund, Kattegat and Skagerrak, Sweden
}

\author{
Elena Dunca · Harry Mutvei · Peter Göransson · Carl-Magnus Mörth · \\ Bernd R. Schöne · Martin J. Whitehouse · Mikael Elfman · Susanne P. Baden
}

Received: 1 March 2007 / Accepted: 28 June 2008/Published online: 7 August 2008

(C) Springer-Verlag 2008

\begin{abstract}
Shells of Arctica islandica collected between 1884 and 2004 from Öresund, Kattegat and Skagerrak (Swedish West Coast) were used to monitor local climate variations and the influence of human activities on the local environment. For this purpose, we analysed the growth, structure and chemical composition of these shells and compared them with shells collected from Kiel Bay, Norway and Iceland. The growth rate of the studied shells registers an NAO periodicity of ca 8 years. However, the observed signal is weak because of other environmental interferences that are either of natural or anthropogenic origin. For example, the oxygen isotope ratios show temperature fluctuation, but also the influx of low salinity water. Higher contents of $\mathrm{S}, \mathrm{N}, \mathrm{Cu}, \mathrm{Zn}, \mathrm{As}, \mathrm{Cd}$ and $\mathrm{P}$ in shell portions formed during the last century are related to human activities such as mining and industrial development. Our study indicates that in order to use Arctica shells as archives of climate change it is necessary to study the
\end{abstract}

\footnotetext{
E. Dunca $(\bowtie) \cdot$ H. Mutvei - M. J. Whitehouse Swedish Museum of Natural History, Box 50007, 10405 Stockholm, Sweden

e-mail: elena.dunca@nrm.se

H. Mutvei

e-mail: harry.mutvei@nrm.se

M. J. Whitehouse

e-mail: martin.whitehouse@nrm.se

P. Göransson

Miljökontoret, 25189 Helsingborg, Sweden

e-mail: peter.goransson@helsingborg.se

C.-M. Mörth

Department of Geology and Geochemistry, Stockholm University, Stockholm, Sweden e-mail: magnus.morth@geo.su.se
}

full range of environmental data that is recorded in the shells by using a multi element and isotope approach in combination with different analytical techniques including investigation of growth rates and shell structure.

Keywords Arctica islandica - Shell chemistry · Shell growth · Oxygen isotopes - Trace elements . Shell structure

\section{Introduction}

For a better understanding of recent climate changes and for prediction of future changes it is essential to reconstruct environmental history and to properly define on one hand the natural periodicities in climate change and on the other hand the human impact on the environment with its effect on climate (Dunca et al. 2005).

\author{
B. R. Schöne \\ Department of Applied and Analytical Paleontology \\ and Increments Research Group, Institute of Geosciences, \\ University of Mainz, 55128 Mainz, Germany \\ e-mail: schoeneb@uni-mainz.de \\ M. Elfman \\ Department of Nuclear Physics, University of Lund, \\ Box 118, 22100 Lund, Sweden \\ e-mail: Mikael.Elfman@nuclear.lu.se \\ S. P. Baden \\ Department of Marine Ecology, Göteborg University, \\ Kristineberg Marine Research Station, \\ 45034 Fiskebäckskil, Sweden \\ e-mail: Susanne.Baden@kmf.gu.se
}


Information about water chemistry, $\mathrm{pH}$, temperature, food supply and anthropogenic pollution can be obtained from the structure, morphology and chemistry of bivalve shells using statistical analysis of measurements of shell growth rate and chemical analytical techniques including ion microprobe (secondary ion mass spectrometry, SIMS), inductively coupled plasma optical emission spectrometry (ICP-OES), nuclear microprobe and neutron activation analysis (Mutvei and Westermark 2001).

These analytical techniques combine a high multi-elemental capacity with high sensitivity and high spatial resolution enabling examination of the distribution of trace elements and isotope ratios within bivalve shells; these data can be used to infer paleotemperature, salinity, $\mathrm{pH}$ and other environmental parameters. However, in many cases we are dealing with ambiguous results, whereby different techniques give different results and give rise to different interpretations of the same material.

The present work deals with these difficulties and suggests some possible strategies. Our focus is on ocean quahog shells, Arctica islandica, from Öresund, Kattegat and Skagerrak (Swedish West Coast).

\section{Materials and methods}

For this study, we used shells of ocean quahog, A. islandica, which were collected between 1884 and 2004, adjacent to the Swedish West Coast, Kiel Bay, Norway and Iceland (Fig. 1; Table 1). These shells had an age distribution between 6 and 230 years (Table 1).

Structural analyses

In order to visualise the microstructure of the shells we used different etching methods on vertical fracture planes of the shells. Mutvei's solution (Schöne et al. 2005a) was used in order to fixate the organic sheets between the crystals and to etch very gently the aragonite. Concentrated sodium hypochlorite was used to dissolve the organic sheets between the crystals without etching the aragonite. The etched fractions were compared with untreated fractions of the same shells.

\section{Dating growth increments}

In order to determine the period in the year during which the annual growth line is developed, the width of the last formed, still incomplete, growth increment was measured and compared with the width of the previous annual growth increment in all studied bivalves, which were collected at different times of the year. In this way, it was possible to conclude how much the shells grow over specific intervals

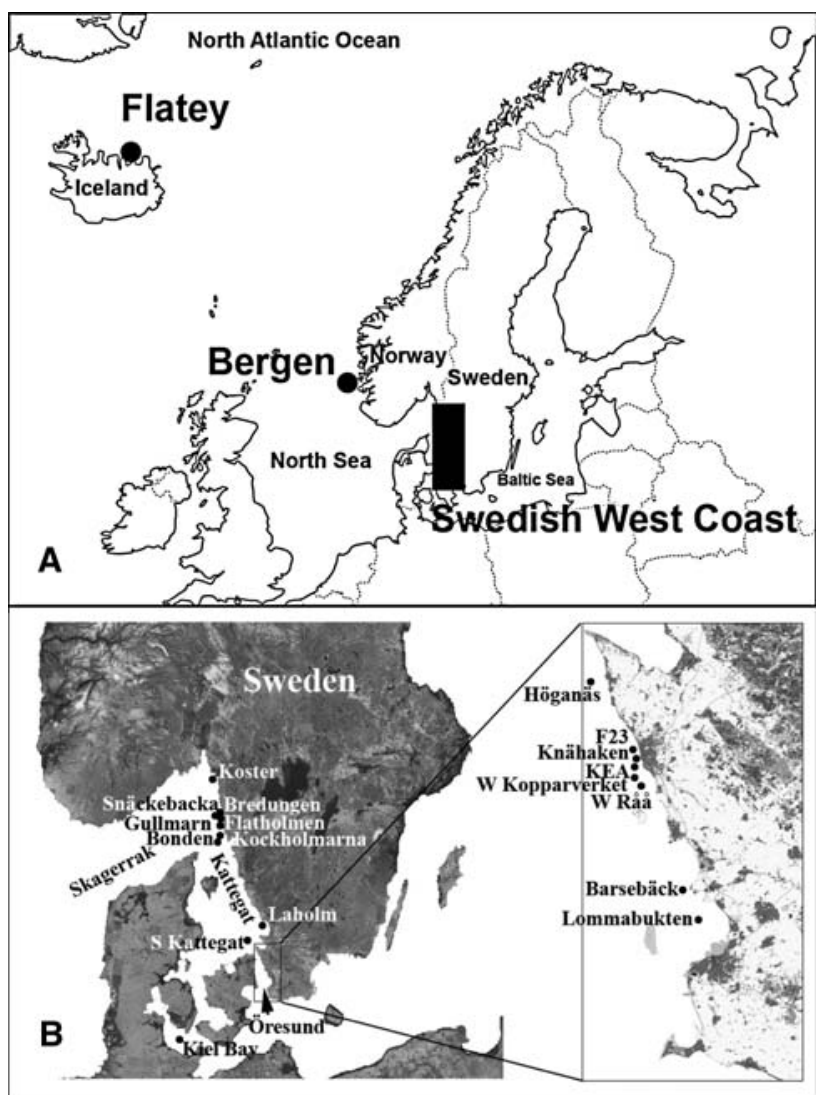

Fig. 1 a Map of localities. b Localities on the Swedish West Coast

between January and December. These observations were compared with the results from isotope analyses. The $\delta^{18} \mathrm{O}$ values of the shell reflect the $\delta^{18} \mathrm{O}$ of the water and temperature at the time of shell deposition. By transforming the shell $\delta^{18} \mathrm{O}$ values into temperature values (using the formula of Grossman and $\mathrm{Ku}$ 1986) it is possible to determine over what temperature range, and hence over what period in the year, the growth line formed.

Shell preparation for growth analyses

The annual growth rate of the shells was measured on vertical shell sections cut from the umbo to the ventral margin along the axes of maximum growth. Each section was prepared using the same method described in previous work (Mutvei 1979; Dunca 1999; Dunca and Mutvei 2001; Schöne et al. 2005a). This method enhances the visibility of annual growth lines and is indispensable for accurate dating of the increments. The annual growth patterns were viewed using both light microscope and SEM at magnifications between $20 \times$ and $500 \times$. Annual growth increments were measured as the distance between two annual growth lines in the shell portion near the periostracum (Fig. 2), using Panopea ${ }^{\circledR}$ image processing software (developed by Peinl and Schöne, University of Frankfurt). The annual 
Table 1 Shell material used in the present study

\begin{tabular}{|c|c|c|c|c|}
\hline Region & Locality & $\begin{array}{l}\text { Date of } \\
\text { collection }\end{array}$ & $\begin{array}{l}\text { No of } \\
\text { shells }\end{array}$ & $\begin{array}{l}\text { Age range } \\
\text { (years) }\end{array}$ \\
\hline & Kiel Bay & 1987 & 5 & $16-54$ \\
\hline Öresund & $\begin{array}{l}\text { W Råå, Lommabukten, Knähaken, W Knähaken } \\
\text { (KEA), W Kopparverket, W Höganäs, Barsebäck, } \\
\text { N Knähaken (F23) } 20 \text { m, N Knähaken (F23) } 30 \text { m }\end{array}$ & 1997-2004 & 27 & $10-223$ \\
\hline Kattegatt & S Kattegat, Laholm & 1995-1999 & 8 & $25-85$ \\
\hline Skagerrak & $\begin{array}{l}\text { Kockholmarna, Gullmarn, Bonden, Snäckebacka, } \\
\text { Bredungen, Flatholmen, Koster }\end{array}$ & 1884-1997 & 21 & $15-160$ \\
\hline North Sea & Bergen (Norway), & 1987 & 5 & $6-130$ \\
\hline $\begin{array}{l}\text { North } \\
\quad \text { Atlantic } \\
\text { Ocean }\end{array}$ & Flatey (Iceland) & 1987 & 1 & 230 \\
\hline
\end{tabular}

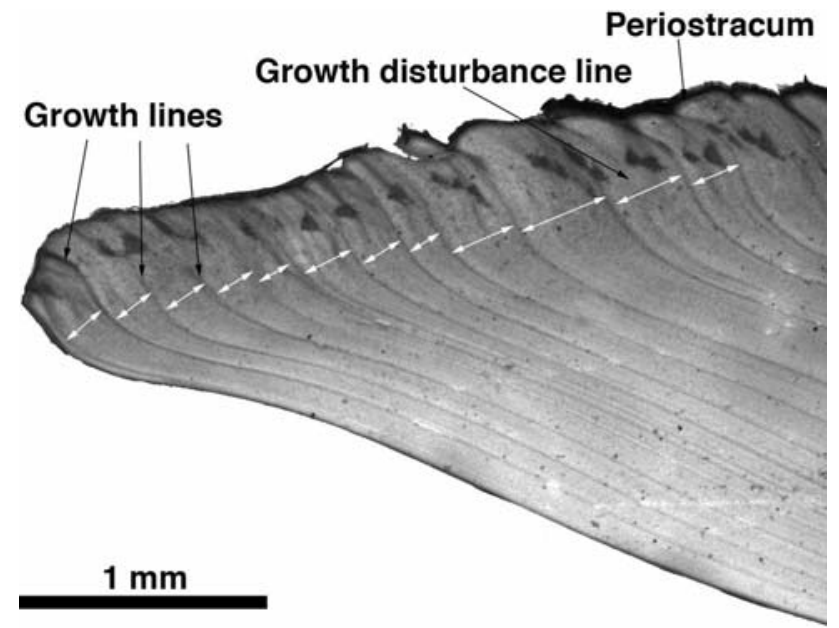

Fig. 2 Growth measurements in transverse shell section

lines are more acid resistant and become more stained, having a dark-blue colour; they are formed when the shell growth temporarily ceases every year during autumn. However, temporary growth cessations may occur within one annual growth increment and in some cases it is difficult to distinguish annual growth lines from intra-annual disturbance lines. In the most critical cases, we used isotope analyses in order to determine if the lines are annual or disturbance lines.

\section{Standardization of growth measurements}

The growth rate of the shells first increases and then decreases with age. Such ontogenetic trends must be removed in order to isolate the environmental signals within shell growth time-series. For this purpose we employed statistical detrending methods similar to those used by dendrochronologists (Cook and Kairiukstis 1990) and described in more detail in our previous work (Dunca 1999; Schöne et al. 2003; Dunca et al. 2005; Schöne et al. 2005b, d). The arithmetic mean of SGI values for each year was calculated for all shells in most of the localities within one region. The same methods (low-pass filtering and spectral frequency analysis with Fast Fourier Transform) described in previous work (Schöne et al. 2003; Dunca et al. 2005) were employed in order to study the growth periodicities.

Growth trends were compared between three regions: Öresund, Kattegat and Skagerrak, and with NAO indexes.

The North Atlantic Oscillation (NAO) is an oscillation of atmospheric mass between the Arctic and the subtropical Atlantic and its index is defined as the pressure difference between the Azores and Iceland (Hurrell 1995; Hurrell et al. 2001). This oscillation triggers the variability of Northern Hemisphere climate and in previous studies (Schöne et al. 2003, 2005b, d) it was demonstrated that annual growth of $A$. islandica shells from North Sea has similar periodicities (7-9 years) to NAO index.

\section{Statistical evaluation of correlation between annual growth series}

The correlation of year-to-year variability between the arithmetic mean of SGI values obtained for the three different regions was quantified using different statistical tests (linear correlation, $t$-statistic and running similarity) described in our previous work (Schöne et al. 2003, 2005c; Dunca et al. 2005).

Preparation for chemical analyses

Isotope analyses

Following the shape of the microgrowth increments, successive samples of aragonite powder were milled along a line from the ventral part of the shell towards the umbo. Milling produces records with high resolution (seasonal and fortnightly) and the operator has good control over the 
spatial and temporal scale of sample acquisition. The sampling resolution was coarser in fast growing shell regions near the umbo (ca $320 \mu \mathrm{m})$ and finer (ca $20 \mu \mathrm{m})$ in slower growing, older shell portions. Each milling yielded between 40 and $120 \mu \mathrm{g}$ of aragonite powder. Samples were analysed with a Finnigan MAT 253 continuous flow mass spectrometer equipped with a Gas Bench II, at the Institute for Geology and Paleontology, J W Goethe University, Frankfurt, Germany.

Totally, 306 samples from nine shells were analysed. Most of the samples were collected from Knähaken (145 samples from three shells) and KEA (128 samples from one shell), Öresund region. From Laholm, Kattegat region, four shells were sampled (120 samples), while from Bonden, North Sea only one shell (13 samples).

\section{Element analysis}

Mass spectrometry Periostracum and the inner shell layer of secondary growth were removed so that the growth increments were free from contamination. A vertical section of 3-4 mm was cut perpendicular to the growth lines from each shell. Further, each shell section was divided into three to five portions with a weight between 10 and $50 \mathrm{mg}$ and with a well-defined number of annual increments. The portions with lower annual growth rate (ca $0.1 \mathrm{~mm}$ ) included 15-20 annual increments while sections with the highest growth rate (ca $2 \mathrm{~mm}$ ) included between one and five annual increments. For cutting and cleaning the shell, we used a $0.1 \mathrm{~mm}$ thin diamond blade attached to a dental drill, Taro Fc-82. The samples were rinsed with ethanol $95 \%$ in ultrasonic bath and thereafter dissolved in $60 \% \mathrm{HNO}_{3}$. The obtained solutions were analysed with an ICP-OES, Varian Vista Ax (inductively coupled plasma using optical emission) at the Department of Geology and Geo-chemistry, Stockholm University and at the Royal Institute of Technology, Sweden. This analytical method has low detection limits (about $1 \mathrm{ng} / \mathrm{g}$ ), thus enabling analysis of most elements with high precision (better than $2 \%$ based on certified standards), which makes it useful for calibration of other analytical methods. Because the spatial resolution is low, this method was used mostly for analyses of long-term trends. Totally, 123 samples were prepared from 27 shells collected at eight localities in Öresund region. One or two shells were analysed per locality except Knähaken, from where 14 shells were analysed.

Secondary ion mass spectrometry From the same shells used for ICP-OES analyses, other vertical sections (3$5 \mathrm{~mm}$ thick and $10 \mathrm{~mm}$ long) were cut out with the diamond saw. Each sample was imbedded in epoxy resin in specially designed forms, with the surface to be analysed facing outwards. The surface was diamond-polished down to a grain size of $0.25 \mu \mathrm{m}$ and then coated with gold. The measurements were made with a large geometry Cameca IMS 1270 ion microprobe at the Nordic ion microprobe facility (NORDSIM) located at the Swedish Museum of Natural History in Stockholm, Sweden. SIMS is one of the most sensitive elemental and isotopic surface analysis techniques, in which a solid sample is sputtered with primary ions of $23 \mathrm{keV}$ energy and the secondary ions that result are analysed with a mass spectrometer. This technique provides a unique combination of extremely high sensitivity for all elements (involving a detection limit down to ppb levels) with a lateral imaging resolution down to $10 \mu \mathrm{m}$ and low background. A series of elements were analysed using both energy filtering and high mass resolution methods to eliminate molecular interferences. Quantification we achieved by using a reference aragonite, a bulk fraction of which was analysed using ICP-OES. For all elements, we used ratios to ${ }^{42} \mathrm{Ca}$. After the measurements, all the sections were viewed under light microscope and to each measurement point was assigned an accurate calendar date. Totally, two shells from Knähaken were analysed.

Nuclear microprobe analyses From the same shells that were used for previous analyses, 10-mm long and 3-mm thick vertical sections were cut with diamond saw. The sections were polished with diamond paste down to $0.25 \mu \mathrm{m}$ grain size and then carbon coated. The samples were mounted on thin glass with carbon glue and then inserted into the sample holder of the nuclear microprobe (NM) at the Department of Nuclear Physics of Lund University, Sweden. Protons from an accelerator were focused by electromagnetic lenses down to a beam of ca $5-\mu \mathrm{m}$ diameter. This ca $3-\mathrm{MeV}$ proton micro-beam was directed at certain points on the shell. The induced X-ray emission was detected and energy-analysed by a semiconductor detector. In order to reduce the predominating Ca peaks in the spectrum a plastic filter was used, which also filtered all the elements lighter than Ca. This method has high spatial resolution (ca $5 \mu \mathrm{m}$ ), which corresponds with fortnightly growth increments, but has a detection limit of ca $20 \mu \mathrm{g} / \mathrm{g}$ because of using a filter and noisy background. After analysis the measured points are visible under light microscope as dark burn marks on the polished shell surface. In order to assign a calendar date to the measurement positions, the sections were cleaned of their carbon coat and then etched with Mutvei's solution for $5 \mathrm{~min}$. The best visibility of annual growth lines and measurement points was obtained using the electron microscope. Totally, five shells were analysed using this method. 


\section{Results}

\section{Shell microstructure}

The microstructure of the Arctica shells has been previously described by many authors (e.g. Bøggild 1930; Thompson and Jones 1977; Thompson et al. 1980; Ropes et al. 1984). Carter (1980) introduced the structural terminology that was also used later by Ropes et al. (1984). According to the latter authors Arctica shells from the east coast of North America consist of two principal aragonite layers covered on the outer surface by an organic rich layer, periostracum. The outer aragonite layer is secreted at the edge of the mantle and has transitional cross-lamellar to cross-acicular (CL) microstructure. This layer is composed of annual growth increments that are separated from each other by annual growth lines. The microstructure of the annual growth lines is different from that of the annual increment, consisting of irregular simple prisms (ISP). Each growth increment exhibits also an outermost, thin, sublayer of homogenous granular structure (HOM).

The entire inner aragonite layer is secreted by the internal surface of the mantle and has a complex crosslamellar to CL structure. The two aragonite layers (inner and outer) are separated by the pallial myostracum, which is composed mostly of ISP.

The Arctica shells from Skagerrak, Norway and Iceland have a structure comparable to that in shells from North America (Fig. 3a). In contrast, the Arctica shells from Kattegat, Öresund and Kiel Bay have a poorly organized
Fig. 3 a Crossed-acicular (CA) microstructure in vertical fracture of a shell from Bergen, North Sea. The fracture surface was treated with concentrated sodium hypochlorite $(5 \mathrm{~min})$ in order to dissolve the organic sheets between the crystals without etching the aragonite. The irregular simple prisms (ISP) of the growth line (gl) is marked by arrow. b Vertical fracture of a shell from Knähaken, Öresund showing a poorly organized homogenous microstructure (HOM). The thin growth line (gl, marked by arrow) lacks the ISP structure and it is difficult to distinguish. This fracture was treated with concentrated sodium hypochlorite for $5 \mathrm{~min}$. c The inner aragonite layer of the same shell as in b shows CA microstructure. Marked by arrow is the pallial myostracum (m) that separates the inner and outer aragonitic layers and is composed mostly by ISP. This fracture was treated with Mutvei's solution for $1 \mathrm{~min}$. d Marked by arrow are thin organic sheets observed between the crystals in shells treated with Mutvei's solution (1 min). e Hitherto, unknown structural components (tubular channels) observed in horizontal cleavages in a shell from Knähaken. The fraction is not treated. f Detail of a tubular channel that is filled with spherical particles
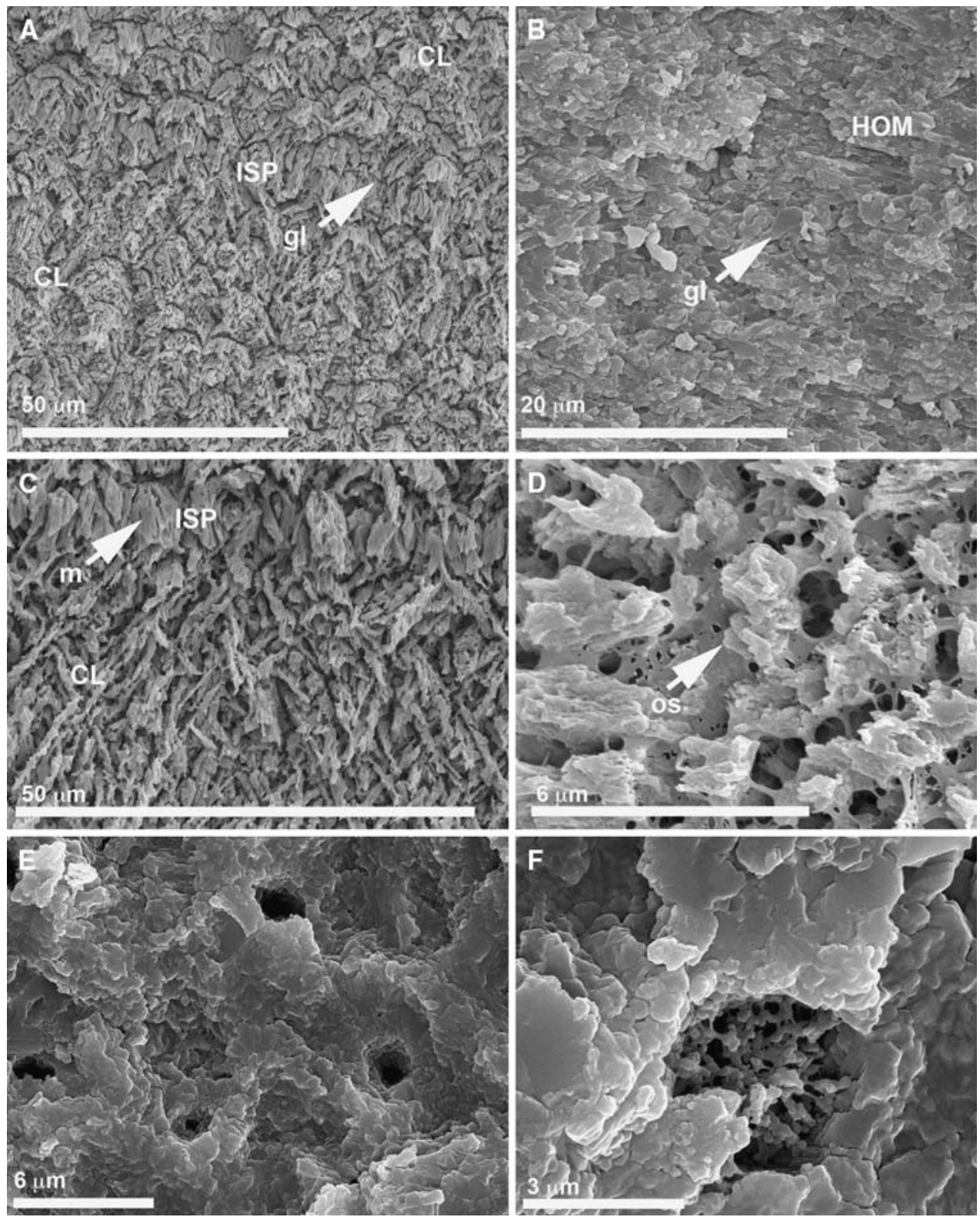
Table 2 Measurements of the last two annual increments and their ratio expressed in $\%$ in all analysed shells

\begin{tabular}{llllll}
\hline Locality & Shell no & Date of collection & $\begin{array}{l}\text { Measurement last } \\
\text { increment }\end{array}$ & $\begin{array}{l}\text { Measurement } \\
\text { previous increment }\end{array}$ & $\%$ \\
\hline W Råå & 3 & 23.04 .1997 & 0.237 & 0.867 & 27 \\
Snäckebacka & 1 & 11.1987 & 0.011 & 3.616 & 0 \\
Laholm & 1 & 05.2000 & 0.176 & 0.362 & 49 \\
Koster & 1 & 11.1986 & 0.005 & 0.082 & 6 \\
Koster & 2 & 11.1986 & 0.003 & 0.127 & 3 \\
Kockholmarna & 3 & 06.06 .1997 & 1.173 & 2.509 & 47 \\
Kockholmarna & 14 & 05.06 .1987 & 3.084 & 6.073 & 51 \\
Kockholmarna & 10 & 05.06 .1987 & 0.052 & 0.089 & 58 \\
Kockholmarna & 1 & 05.06 .1987 & 0.162 & 0.265 & 61 \\
Knähaken & 6 & 08.10 .2003 & 0.000 & 1.191 & 57 \\
Knähaken & 8 & 11.05 .1998 & 0.119 & 0.209 & 0 \\
Knähaken & 30 & 16.09 .2002 & 0.000 & 0.194 & 0 \\
Knähaken & 2 & 16.09 .2002 & 0.000 & 0.104 & 15 \\
Knähaken & 2 & 05.12 .2001 & 0.139 & 0.909 & 65 \\
Flatey & 1 & 06.1987 & 0.060 & 0.092 & 21 \\
Flatholmen & 9 & 06.02 .1989 & 1.194 & 5.575 & 17 \\
Flatholmen & 4 & 06.02 .1989 & 0.688 & 4.136 & 91 \\
Bredungen & 1 & 25.07 .1988 & 0.482 & 0.529 &
\end{tabular}

microstructure. The outer, principal aragonitic layer has mostly a HOM (Fig. 3b) and the thin growth lines (gl) are less well expressed, lacking the prismatic structure. Only the inner aragonite layer shows a complex CL structure. Thin organic sheets occur in the interspaces between the crystals (Fig. 3d). Numerous, hitherto unknown, tube-like channels were observed on horizontal cleavage planes in all shells used for this study. These channels are surrounded by radially arranged crystals and are filled with spherical particles (Fig. 3e, f).

\section{Shell growth}

The shell growth in bivalves collected in November (measured from the last annual growth line) is ca 5\% of the previous annual growth increment, while in those collected in February it is ca 20\%, in April ca 30\%, in June ca $60 \%$ and July ca $90 \%$ (Table 2). Shells collected in September and the beginning of October do not have any increment after the last annual growth line. This indicates that the growth of an annual increment starts between the end of October and beginning of November and ceases (producing the annual growth line) during August-September in the next calendar year.

These observations correspond with the results from isotope analyses (Fig. 4). The values of $\delta^{18} \mathrm{O}$ at the growth lines are less than the maximum values. If the $\delta^{18} \mathrm{O}$ values are transformed into temperature values using the Grossman and $\mathrm{Ku}$ (1986) function:
$F(x)=20.6-(4.34 *(x-(a-0.27)))$

where $x$ is the $\delta^{18} \mathrm{O}$ of the shell, $a \delta^{18} \mathrm{O}$ of the water, then the isotope measurements indicate that the growth lines form in autumn when the water temperature has begun to decrease. The next annual increment starts growing after the maximum of water temperature is reached, i.e. by the end of autumn (November in most cases). The water temperature variation at the bottom (depth of $15 \mathrm{~m}$ ) is shifted by 4 weeks in comparison with the water temperature at the surface (Fig. 5).

A variation of shell thickness was observed in bivalves from different localities (Fig. 6). There is a gradient of decreasing shell thickness from the North to the Baltic Sea (Kiel Bay) that is not related to age.

Shell growth analyses using linear regression show that the variation in annual growth rate is similar in most localities from Öresund; correlation coefficient $r$ varies from 0.27 to 0.57 .

The annual growth rate of Icelandic shell has been incorporated into the mean of Skagerrak as there was not sufficient shell material to construct mean growth curves for North Atlantic Ocean.

Linear regression analysis of the averaged SGI values revealed a weak positive correlation $(r=0.18)$ between Skagerrak and Öresund region. Yet, the correlation coefficient is higher $(r=0.32)$ if the high frequency periodicity is filtered using moving average (Fig. 7a, b). The depth of the water does not influence growth patterns. Shells from 
Fig. $4 \delta^{18} \mathrm{O}$ values of a juvenile Arctica islandica shell from Knähaken. The positions of the annual growth lines are marked by vertical lines on the graph and dark arrows on the transverse section of the measured shell. The light arrows mark growth disturbance lines. On the $x$ axis is plotted the distance $(\mathrm{mm})$ from the ventral shell margin to each measurement point and on $y$ axis are plotted the $\delta^{18} \mathrm{O}$ values (\%o) and temperature $\left({ }^{\circ} \mathrm{C}\right)$ calculated from the $\delta^{18} \mathrm{O}$ values

\section{Knähaken}
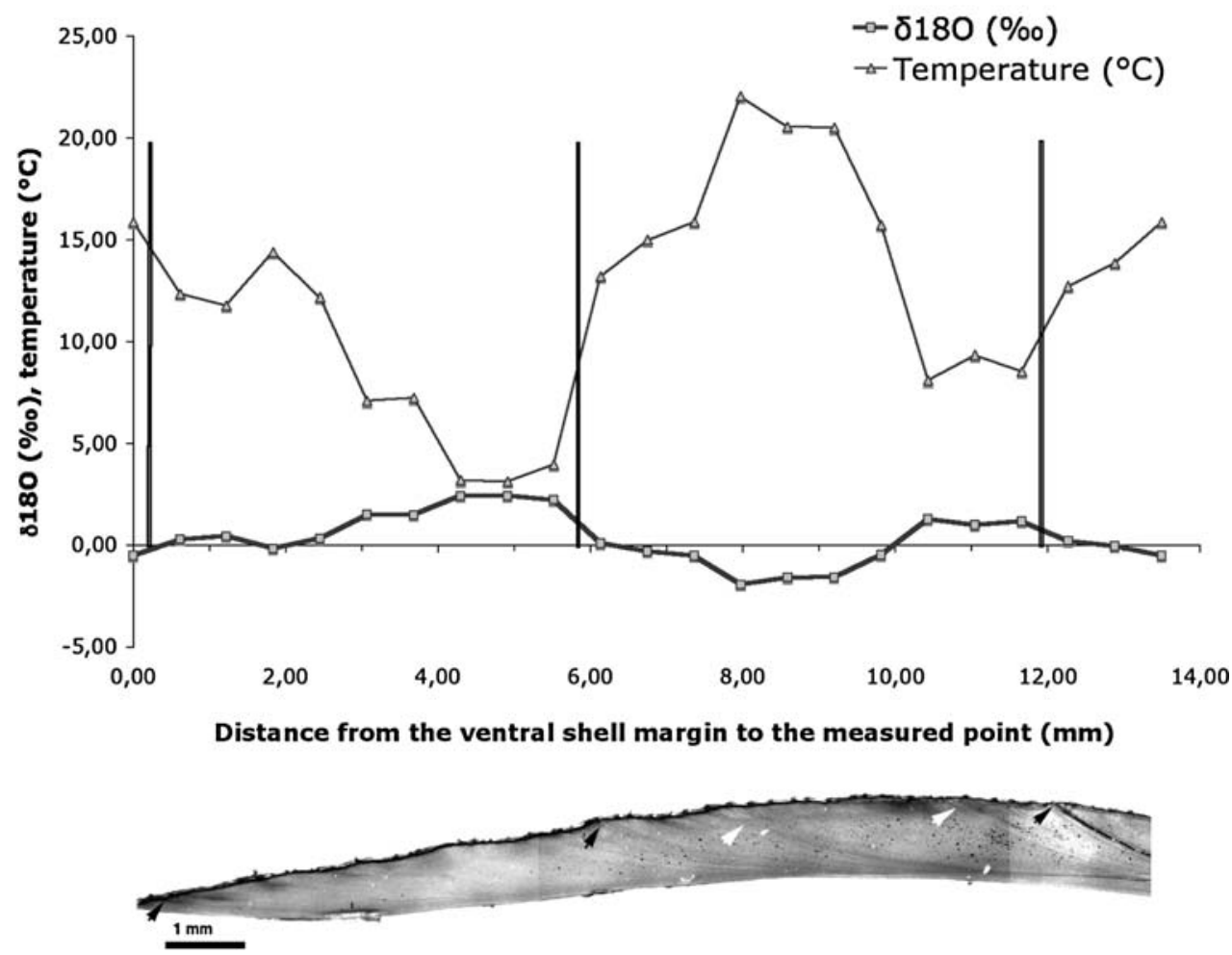

20-m depth have a similar growth pattern $(r=0.57)$ to shells from 30-m depth (Fig. 7c).

Continuous-wavelet analyses indicate that the shell growth in Skagerrak has a strong 7-9 years periodicity, whereas in Öresund the growth has a stronger 20 years periodicity. The 7-9 years periodicity is present in Öresund shells as well but is much weaker (Fig. 8).
Chemistry

Inductively coupled plasma optical emission spectrometry gives an opportunity to determine long-term trends in the chemical composition of the shells, which reflect changes in water chemistry at the time of shell deposition (Mutvei and Westermark 2001).
Fig. 5 Water temperature variations measured at the surface by National oceanic and atmospheric administration (NOAA) compared to available data set of water temperatures measured at the bottom (at $15-\mathrm{m}$ depth) in Lommabukten by Environmental board of Helsingborg. There is an offset of 4 weeks between the peaks of the two data sets

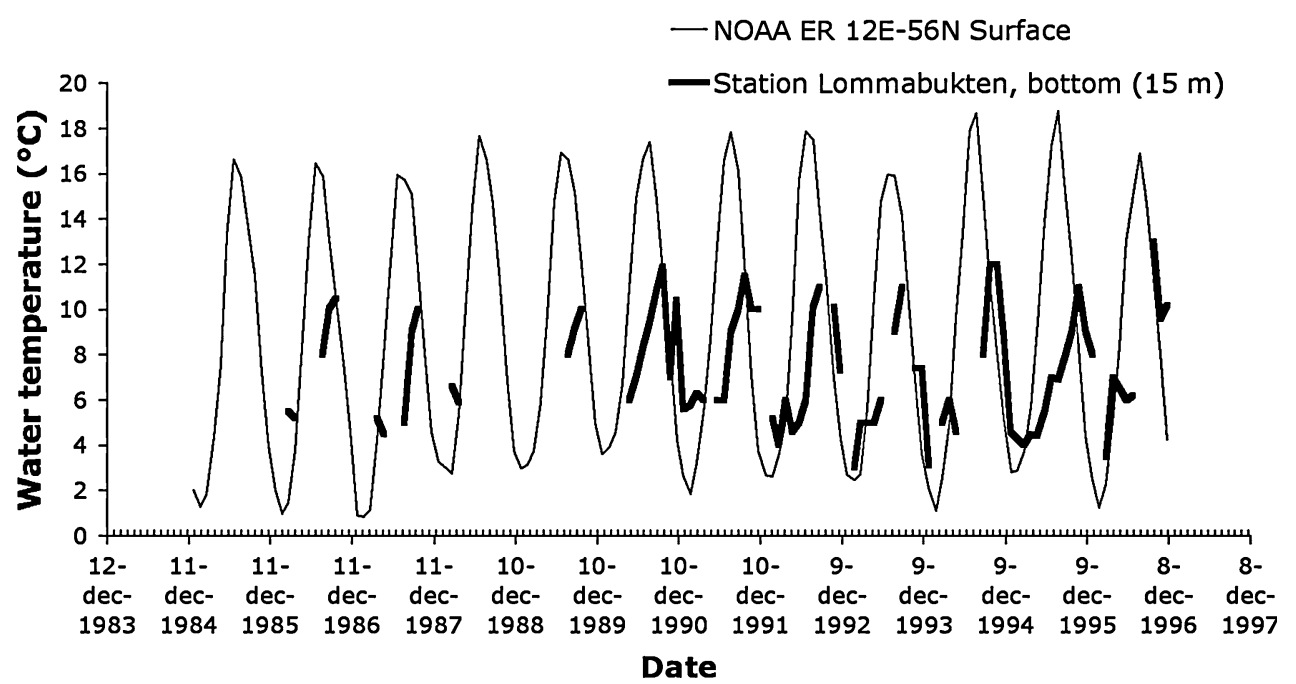




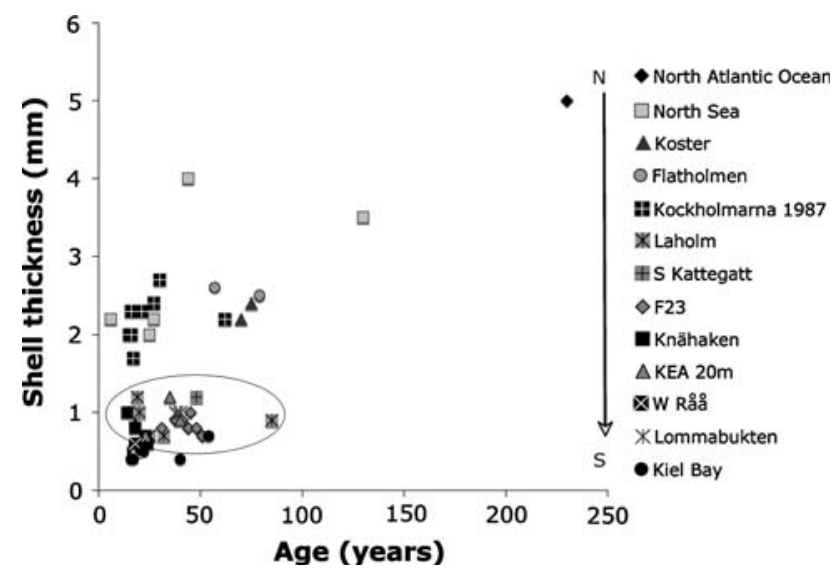

Fig. 6 Diagram showing shell thickness versus age in bivalves from localities that were sorted from the most northern, Flatey, Iceland, to the most southern, Kiel Bay. Shells from North Atlantic Ocean, North $\mathrm{Sea}$, as well as from Skagerrak are thicker than the shells from $\mathrm{S}$ Kattegat and Öresund (within the marked area), while shells from Kiel Bay are thinner (bellow the marked area, except one shell)

In Arctica shells from Öresund the amount of iron (Fe), phosphorus (P), arsenic (As) and cadmium (Cd) generally decreases from nineteenth century until present (Fig. 9). However, the amount of these elements varies in different localities. For example, the amount of $\mathrm{P}$ in shells from Höganäs, Barsebäck, W Kopparverket and Lommabukten is four times higher than in shells from other localities. The amount of $\mathrm{Cd}$ decreases from nineteenth century until present time only in shells from Knähaken that were collected at 30-m depth. In all other shells, the Cd amount has the same level as in the middle of nineteenth century, decreasing only after 1990.

In shells from Knähaken (collected at $30 \mathrm{~m}$ depth) the amount of sulphur (S) slightly decreases from 1860 until ca 1930, then it increases between 1930 and 1960, and between 1980 and 1990; it decreases between 1960 and 1980, and after 1990 (Fig. 10a). The amount of Nitrogen $(\mathrm{N})$ in all analysed shells is more or less stable from 1860 until ca 1945, then it increases until 1985; after that it decreases in all shells from Knähaken, but increases in shells from Lommabukten (Fig. 10b). Copper $(\mathrm{Cu})$ and Zinc (Zn) amount strongly decreases from 1860 until the beginning of the nineteenth century and then it is more or less constant until present in all analysed shells (Fig. 10c, d). Shells from Barsebäck, Höganäs, F23 and W Råå have higher amount of both $\mathrm{Cu}$ and $\mathrm{Zn}$. In Knähaken, the shells from shallow water $(15-20 \mathrm{~m})$ show two to three times higher amounts of $\mathrm{Cu}$ and $\mathrm{Zn}$ than the shells from deeper water (30 m) (Fig. 10c, d).

The amount of $\mathrm{Fe}$ decreases exponentially during the last 150 years according to the combined data from all analysed shells. Measurements with high temporal resolution by SIMS show low levels of Fe during the last 60 years, with some higher peaks in 1943, 1981 and 1986 (Fig. 11). Mapping with nuclear microprobe shows that Fe is uniformly distributed through the thickness of the shell
Fig. 7 a Diagram showing mean annual growth curves for Skagerrak and Öresund regions. The annual growth rate of Icelandic shell has been incorporated into the mean of Skagerrak region. b Filtrated mean annual growth curves for Skagerrak and Öresund regions using moving average with a step of 10. $\mathbf{c}$ The mean annual growth curve of three shells collected at 20-m depth has similar annual growth pattern to a shell collected at 30-m depth from the same locality (F23)
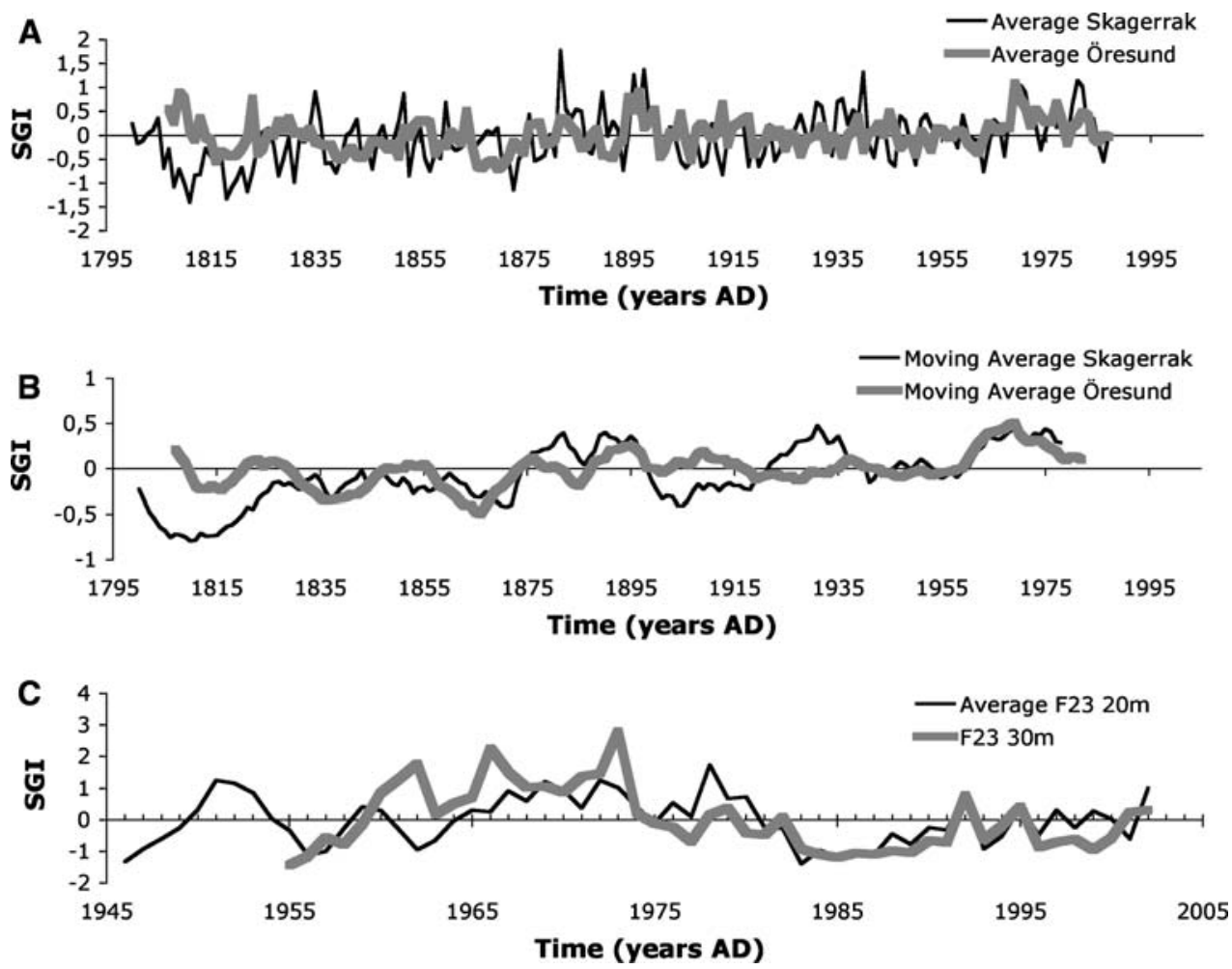


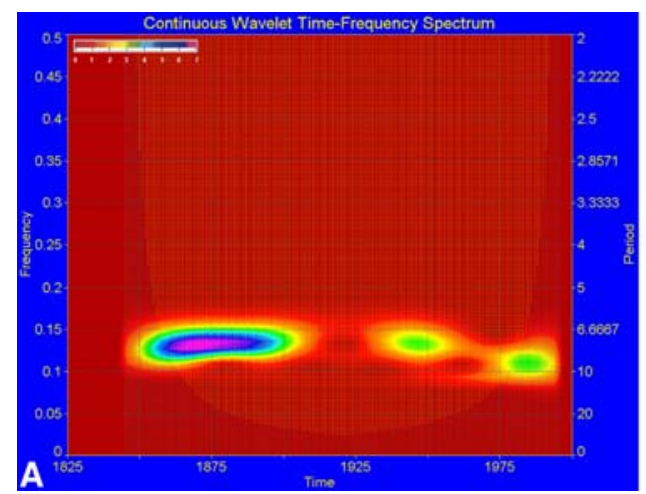

Fig. 8 a Continuous-wavelet spectrum of SGI in a 160-years-old shell from Gullmarn (Skagerrak region) indicates that the shell growth has strong 7-9 year periodicity. b Continuous-wavelet

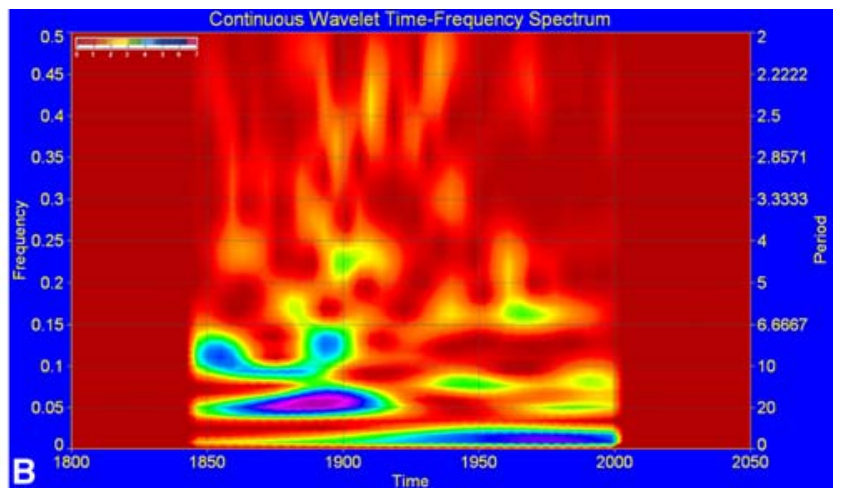

analyses spectrum of averaged SGI of five shells from Öresund indicate that the shell growth has stronger 20 years periodicity, while the 7-9 years periodicity is much weaker

\section{A}
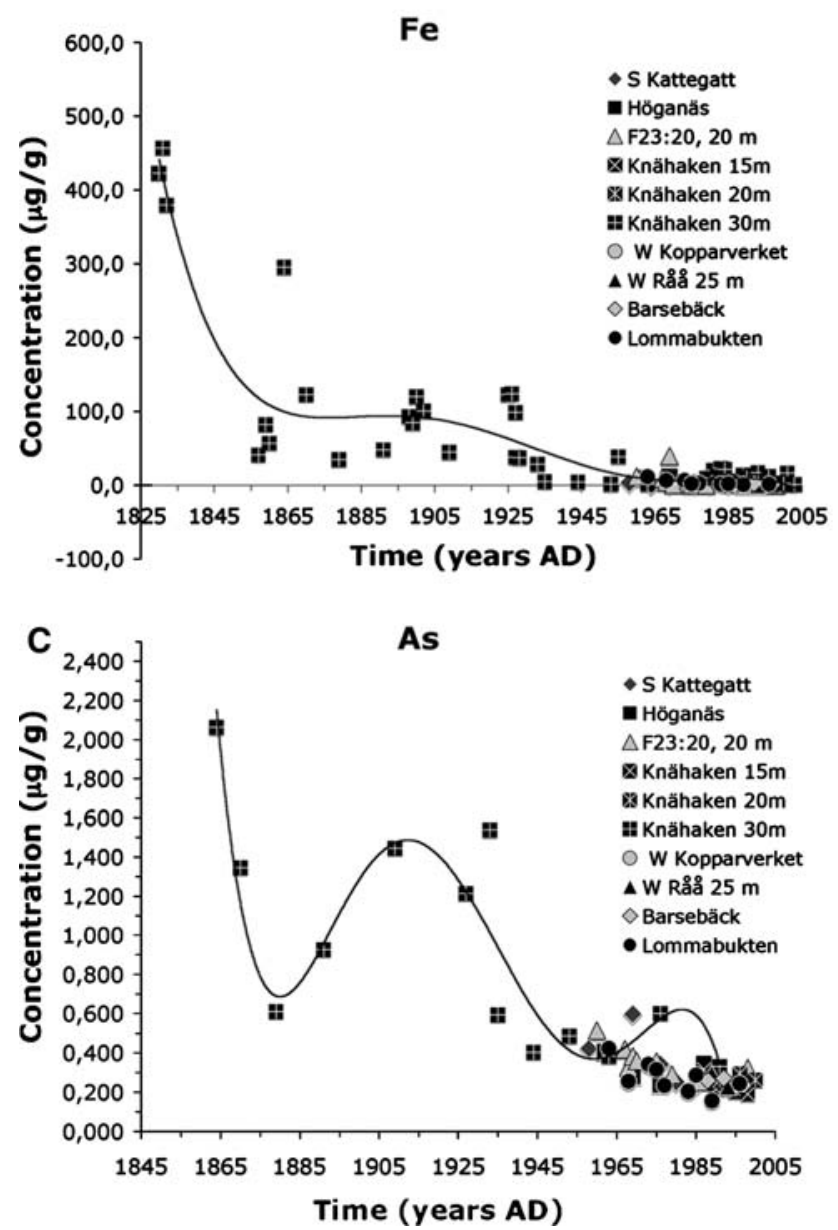

Fig. 9 Trends (described by polynomial and exponential curves, respectively) in $\mathrm{Fe}, \mathrm{P}$, As and $\mathrm{Cd}$ distribution within shells from Öresund and S Kattegat. a The amount of Fe decreases exponentially during the last 150 years in all analysed shells. b The amount of $\mathrm{P}$ decreases for the last 150 years in shells from Knähaken collected at 30-m depth, from S Kattegat, F 23 and W Råa. The highest amounts were recorded in shells from Knähaken collected at 15-m depth, from
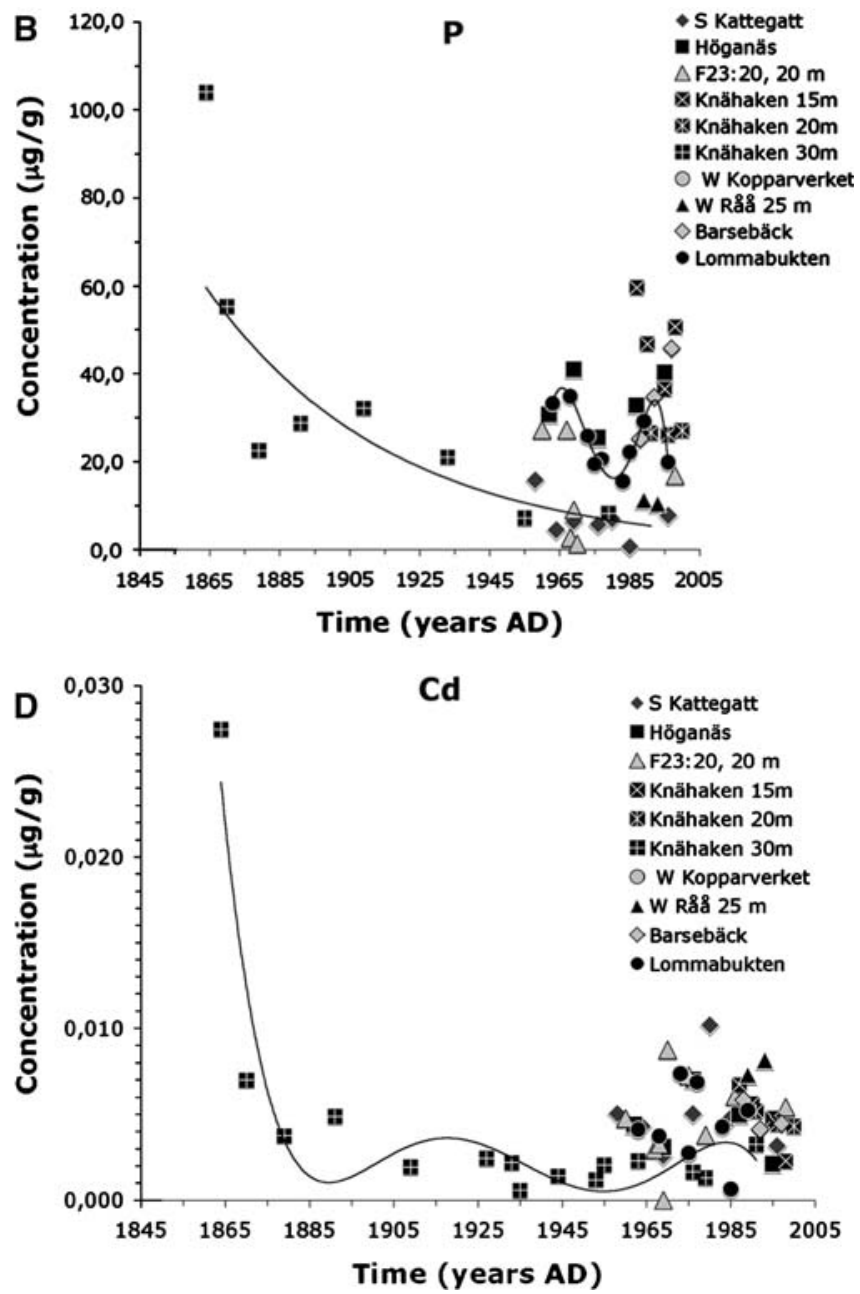

Höganäs and Barsebäck. $\mathbf{c}$ The distribution of As is similar to that of $\mathrm{Fe}$ decreasing exponentially for the last 150 years in all analysed shells. d The amount of $\mathrm{Cd}$ is decreasing from nineteenth century until present time only in shells from Knähaken collected at 30-m depth. In all other shells the $\mathrm{Cd}$ amount has the same level as in the middle of nineteenth century, but slightly decreasing after 1990 

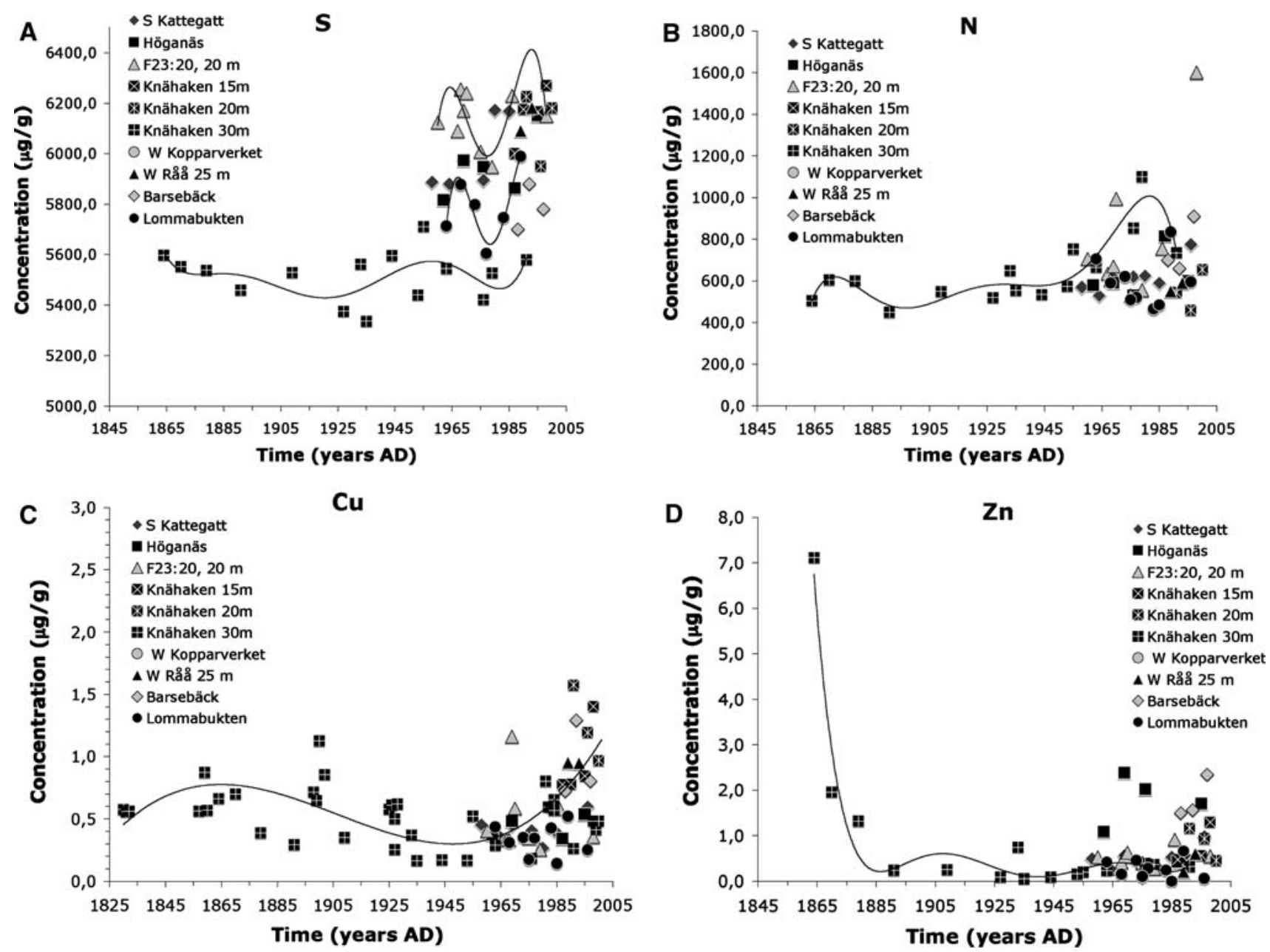

Fig. 10 Trends (described by polynomial curves) in $\mathrm{S}, \mathrm{N}, \mathrm{Cu}$ and $\mathrm{Zn}$ distribution within shells from Öresund and S Kattegat. a In shells from Knähaken (collected at 30-m depth) the amount of S slightly decreases from 1860 until ca 1930, between 1960 and 1980, and after 1990; higher amounts were recorded between 1930 and 1960, and between 1980 and 1990. Highest amounts were found in shells from F 23, Knähaken at 15- and 20-m depth, Höganäs, Lommabukten and Barsebäck, as well as in S Kattegat. b The amount of N is stable from 1860 until ca 1945, then it increases until 1985 in all analysed shells;

after that it decreases in all shells from Knähaken, but increases in shells from Lommabukten. The highest amounts were measured in shells from F 23 and Barsebäck. c Cu amount strongly decreases from 1860 until the beginning of nineteenth century and then it is more or less constant until present in all analysed shells. Shells from Barsebäck, Höganäs, F23 and W Råå, as well as shells from shallow water in Knähaken (15-20 m) have higher amount of both $\mathrm{Cu}$ and $\mathrm{Zn}$. d $\mathrm{Zn}$ show similar variations to $\mathrm{Cu}$

Fig. 11 Amount of $\mathrm{Fe}$ and $\mathrm{Mn}$ measured with high temporal resolution by SIMS on a shell from Knähaken (30 m), Öresund. During the last 60 years the amount of $\mathrm{Fe}$ is generally low and has a decreasing trend (dotted line). Some higher peaks were measured in 1943, 1981 and 1986. Mn has also a decreasing trend but not so pronounced

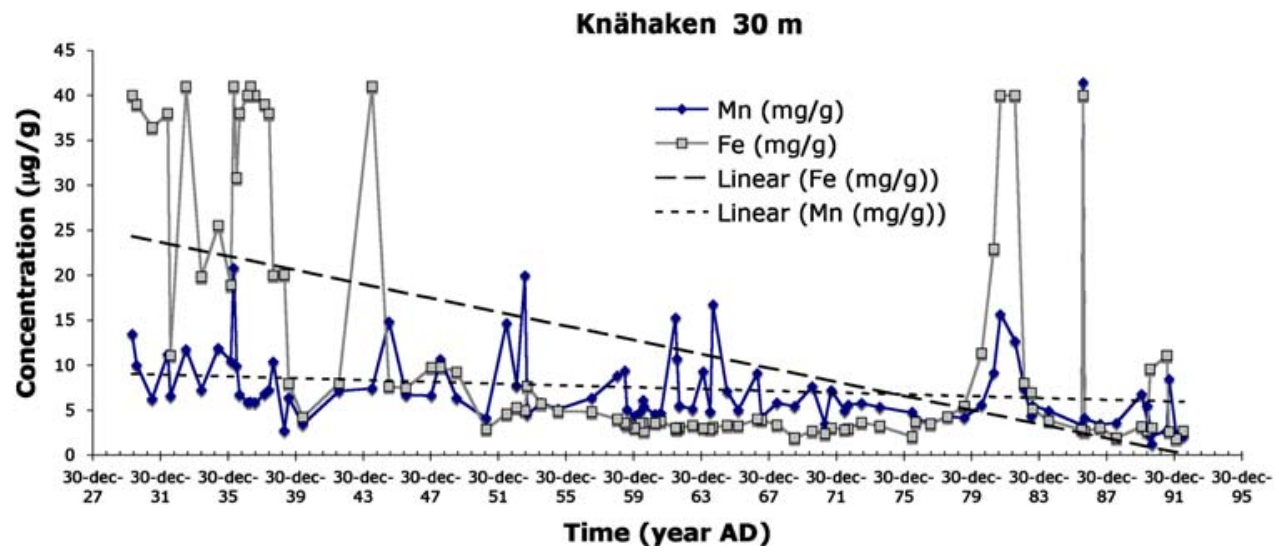


with accumulation in the periostracum (Fig. 12a). Mn shows a similar distribution to Fe (Fig. 11). Strontium ( $\mathrm{Sr}$ ) is not evenly distributed within the Arctica shells. NM mapping shows seasonal variations of $\mathrm{Sr}$ with higher amounts around the annual growth lines (Figs. 12b, 13a). $\mathrm{Sr}$ is found only in the aragonite shell layers and not in the periostracum (Fig. 12b). ICP-OES analyses do not show any long-term trends in Sr distribution (Fig. 13b).

Isotope analyses demonstrate lower values of $\delta^{18} \mathrm{O}$ in shells from Öresund region compared to shells from Kattegat (Fig. 14). In shells from Öresund $\delta^{18} \mathrm{O}$ values range from -1.68 to +2.54 while in shells from Laholm and Bonden from +0.39 to +3.26 (Fig. 14a, b, c). Between growth lines the $\delta^{18} \mathrm{O}$ values show distinct annual cycles. However, the strong negative $\delta^{18} \mathrm{O}$ values may indicate influxes of freshwater as the water temperature does not oscillate that much. Unfortunately, there are no salinity and water $\delta^{18} \mathrm{O}$ data sets available for the time period that was analysed in shells and no direct comparison can be made. However, the available salinity data from Öresund region show that there are strong salinity variations (21 to $35.5 \%$ ) in this region, mostly in late autumn, winter and early spring (Fig. 14d; Lintrup and Jakobsen 1998). The negative $\delta^{18} \mathrm{O}$ values measured in shells are close to the annual growth lines, which may correspond with the freshwater influxes (Fig. 14a).

\section{Discussion and conclusions}

Shells from Kiel Bay and Öresund are considerably thinner and smaller, and have less organised microstructure (a higher proportion of HOM) than shells from Skagerrak, North Sea and North Atlantic Ocean. Many of these shells have also numerous growth disturbance lines developed as a result of growth cessation during the winter and spring. Because the low salinity influxes occur usually in late autumn, winter and spring (Lintrup and Jakobsen 1998) it is most probable that the bivalves react to the salinity changes by closing their shell and stopping growth. The isotope analyses of the shells confirm this hypothesis.

Despite this, the annual growth rate of Öresund shells is similar to Skagerrak, North Sea and North Atlantic Ocean shells. However, the ca 8-year periodicity in shell growth that is associated with the NAO is weaker in Öresund shells in comparison with Skagerrak shells and their use in models for temperature reconstructions is not recommended. Also, these shells cannot be used in reconstructing water temperatures from oxygen isotope analyses as the water salinity varies from 20 to $35 \%$.

Other chemical analyses are more useful in disclosing the environmental archives within these Arctica shells. NM is very useful for mapping the elemental distribution within the annual increments while the ICP-OES is useful for long-term trends of a large spectrum of elements. SIMS is the best tool to resolve seasonal variations of several trace elements and even isotopes within shells.

Previous studies have shown that the distribution of $\mathrm{Cu}$, $\mathrm{Zn}, \mathrm{Cd}, \mathrm{As}, \mathrm{S}, \mathrm{P}, \mathrm{N}$ in shells reflects changes in the water environment that are mainly due to human activities such as mining, agriculture, construction and industrial production (Mutvei el al. 1994; Westermark et al. 1996). Helsingborg is a major regional centre of trade, industry and transport (Johannesson 1980). Coal mining started in this region (Höganäs) in the beginning of the seventeenth century and lasted until 1930. The wastewater from the mines was discharged directly into the sea through a channel that was constructed in 1801. Helsingborg became industrialised during the 1850s when textile factories and iron foundries were established and artificial fertilizers were introduced in farming. At the beginning the fertilizers (guano) were imported but in 1875 a local factory for super-phosphates started to produce fertilizers (Johannesson 1980). In recent times this factory has developed into a
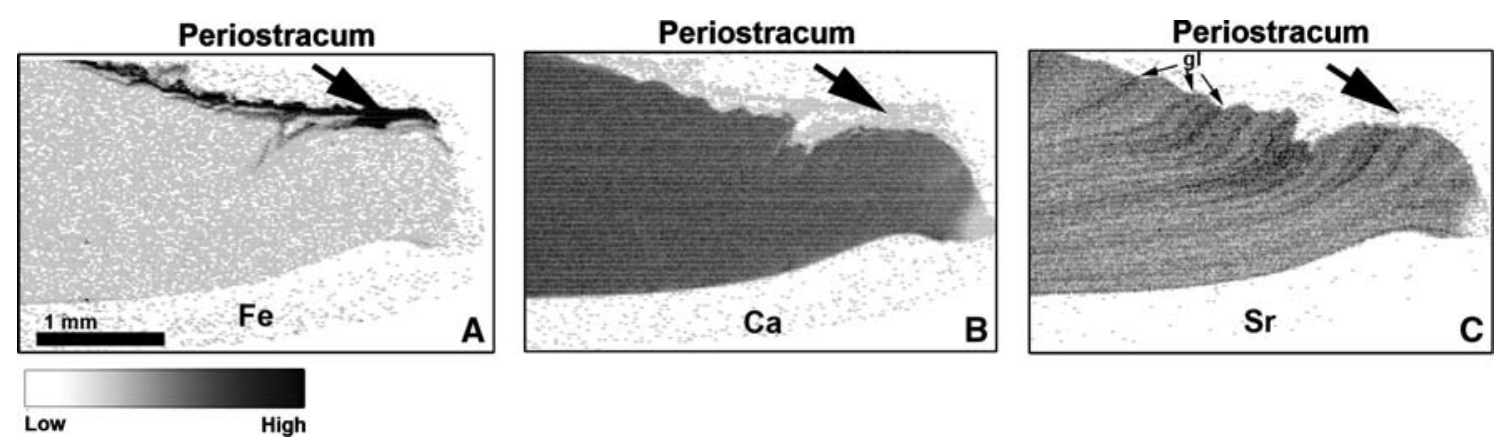

Fig. 12 Transverse section of Arctica islandica shell from Knähaken, Öresund, analysed by mapping with nuclear microprobe. Each pixel stands for a measured value. Darker pixels represent higher amounts. a Fe have an even distribution trough the aragonitic part of the shell and accumulates mainly in the outermost organic rich layer, periostracum. b $\mathrm{Ca}$ has also an even distribution through the aragonitic part of the shell and only very low amounts in the periostracum. c Sr is found only in the aragonitic part of the shell and not in the periostracum and shows seasonal variations with higher amounts around the growth lines (gl) 
Fig. 13 a Seasonal variation of $\mathrm{Sr}$ concentration in a shell from Knähaken, Öresund, analysed with NM. Below the diagram it is an illustration (light microscope picture) of the untreated surface of the transverse shell section on which the measurement were performed. The measurement points are seen as brown burn marks. The oblique dark lines are growth lines (dark arrows and vertical lines on the graph), as well as and growth disturbance lines (light arrows on the shell section). Peaks of higher concentration are distributed around growth lines. b $\mathrm{Sr}$ concentrations measured in 14 shells using ICP-OES. The data do no show any long-term trend
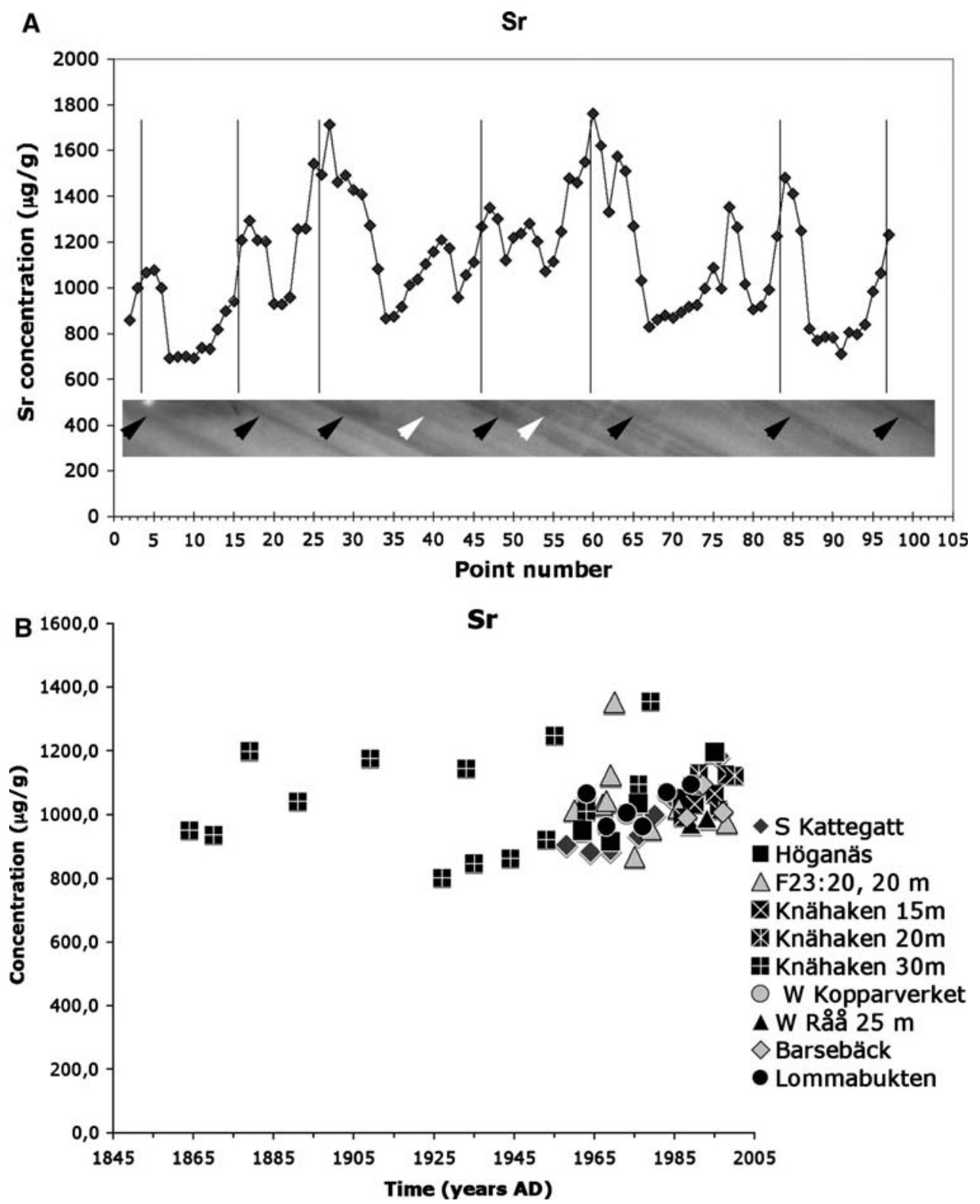

chemical industry group that produces chemicals for the pulp and paper industry. In 1886, a factory for $\mathrm{Cu}$ extraction (Kopparverket) was opened in S Helsingborg and ca 15 years later was moved to Råå (Johannesson 1980). In Barsebäck a nuclear power plant started to produce electricity in 1975 but 30 years later it was closed. These are the several examples of human activities in the Öresund region that had a strong impact on the environment of this region, especially in the nineteenth century and at the beginning of twentieth century. Even though the pollution from industries and farming has decreased substantially since the nineteenth century, there are still high concentrations of trace elements such as $\mathrm{Cu}, \mathrm{Zn}, \mathrm{As}, \mathrm{Cd}, \mathrm{Cr}, \mathrm{Ni}$, $\mathrm{Pb}, \mathrm{Hg}, \mathrm{S}$ and $\mathrm{P}$ both in sediment and in soft tissues of animals and plants (Göransson and Karlsson 1997;
Göransson et al. 2003; Rühling 2005). Our measurements on shells of $A$. islandica show that the amount of $\mathrm{Cu}, \mathrm{Zn}$, As, Cd and $\mathrm{P}$ generally decreases over the last 150 years. However, in shells from Höganäs, N Knähaken (F23), Barsebäck and $\mathrm{W}$ Råå the amounts of $\mathrm{Cu}, \mathrm{Cd}, \mathrm{Zn}, \mathrm{S}$ and $\mathrm{P}$ are higher than in the rest of the shells. Similar results were obtained from chemical analyses of bryophytes (Rühling 2005), marine sediments and soft parts of Mytilus edulis (Göransson et al. 2003).

The amount of most trace elements is higher in shallower waters (15-20 m) of Knähaken, which indicates that the strong halocline in the region may prevent the transport of substances from the surface water to the deep water.

The main source of $\mathrm{S}$ in Öresund region is from air pollution by $\mathrm{SO}_{2}$ gas that results from the combustion of fossil 
Fig. 14 a The $\delta^{18} \mathrm{O}$ composition of Arctica shell from shallow water $(15-\mathrm{m}$ depth) in Knähaken, Öresund, show strong variations ranging from -1.68 to $+2.54 \%$. Most of the negative $\delta^{18} \mathrm{O}$ values are close to the growth lines (arrows and longitudinal bars). $\mathbf{b}, \mathbf{c}$ The $\delta^{18} \mathrm{O}$ composition of shell from Laholm and Bonden, Kattegat, show no negative values and ranges from 1 to $3 \%$. d Salinity and water temperature data sets for Lommabukten (from Environmental board of Helsingborg). Low salinity influxes occur mostly in late autumn, winter and early spring

\section{A \\ Knähaken 15 m}

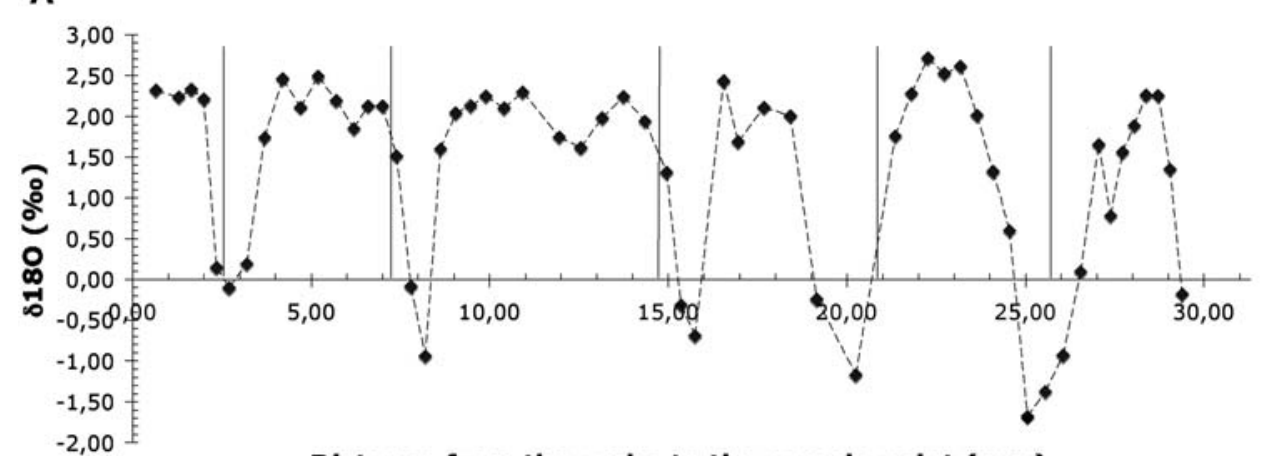

Distance from the umbo to the sample point $(\mathrm{mm})$

Laholm st 3 no 1

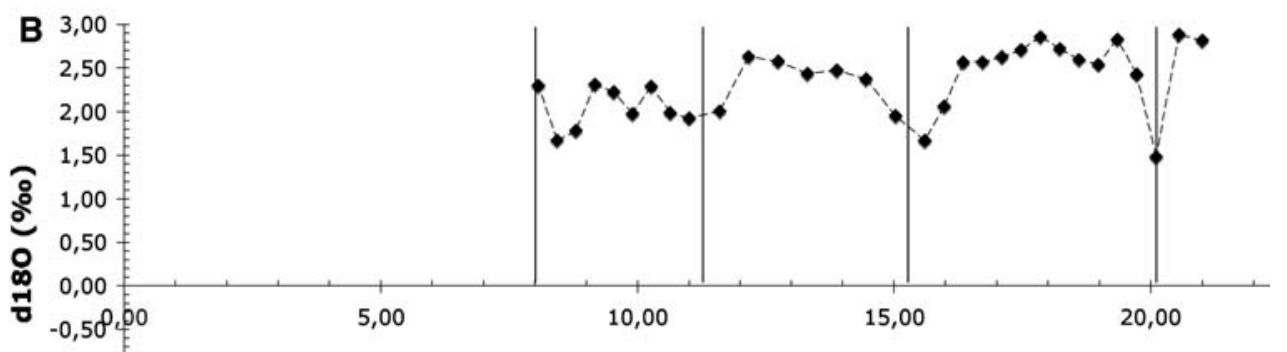

Distance from the umbo to the sample point ( $\mathrm{mm}$ )
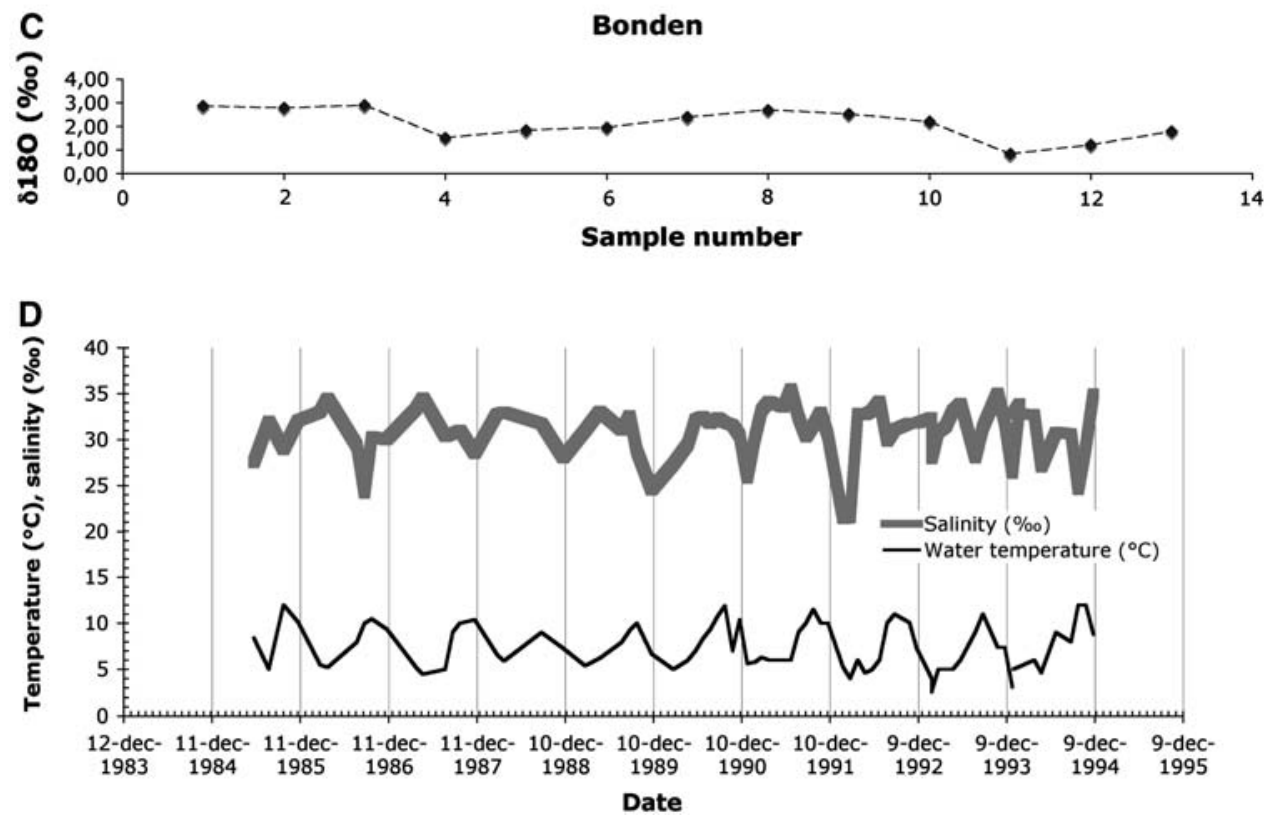

fuels for energy production, industry and transport ( $\mathrm{k}$ kersson 1993). The air pollutants have been monitored in this region by the organisation Skånes Luftvårdsförbund since 1988. Their measurements show that the $\mathrm{SO}_{2}$ levels in the air have strongly decreased since 1980, which is apparently reflected in our measurements in Arctica shells. Unfortunately, no air measurements were available before 1980 .
The increase of $\mathrm{N}$ level occurs most probably due to an increase in the use of fertilizers in farming (Anonymous 1993).

Levels of $\mathrm{Fe}$ and $\mathrm{Mn}$ decrease dramatically in the last 150 years, but the cause of this is not yet understood. There is some evidence that the incorporation of $\mathrm{Fe}$ into $A$. islandica shells is age-related (Westermark et al. 1996) and 
this can explain the highest measured values. However, measurements made on shells of the same age demonstrate that there is a real trend of decreasing $\mathrm{Fe}$ level in the last 150 years. Measurements of $\mathrm{Fe}$ in bryophytes (Rühling 2005) show decreasing values from 1990 to 2005. It is suggested by the same author that $\mathrm{Fe}$ is leaching from farming areas. If this was the case $\mathrm{Fe}$ would leach through the freshwater system into the sea and finally become incorporated into bivalve shell. Pollution from iron foundries is another possible explanation of our results as the number of iron foundries in this region has decreased since the nineteenth century. NM mapping shows that $\mathrm{Fe}$ is evenly distributed through the aragonite layers of the shell and accumulates mostly in periostracum, the outmost organic shell layer. This indicates that Fe binds to the organic material in the shell, i.e. the sheets that surround aragonite crystals, which may explain the homogeneous distribution.

Mn distribution in the shells follows that of Fe. This suggests that even Mn binds to the organic parts of the shells. Previous studies on freshwater bivalve shell have shown that the amount of $\mathrm{Mn}$ is negatively correlated to the amount of dissolved $\mathrm{O}_{2}$ in the water (Nyström et al. 1996). In this way the amount of $\mathrm{Mn}$, and possibly $\mathrm{Fe}$, in shells could indicate anoxic periods at the bottom. In the case of Arctica shells this would be difficult to prove because usually the anoxic periods occur during autumn when the bivalves do not grow their shells.

$\mathrm{Sr}$ is distributed only in the aragonite shell layer, possibly substituting for $\mathrm{Ca}$ ions in the aragonite. Higher amounts of $\mathrm{Sr}$ around the growth lines or lines of growth disturbance could be an accumulative effect as the aragonite crystals are smaller in these shell portions.

In conclusion, our studies demonstrate that the growth, structure and chemical composition of Arctica shell reflects both natural environmental changes and changes induced by human activities. For this reason, in order to use Arctica shells as archives for climate change models it is necessary to study the full range of environmental data recorded in the shells. In order to achieve this goal we suggest combining investigations on shell growth rates and structure with chemical investigations using different analytical techniques that have a high multi-elemental capacity, high sensitivity and high spatial resolution.

The results of our chemical analysis indicate that the pollution has decreased in Öresund since the nineteenth century and is restricted to the region near the industries.

Acknowledgments This study was financially supported by Region Skånes miljövårdsfond and NORDSIM. We thank our dear colleague Torbjörn Westermark, who passed away before the project was finished. Without his enthusiasm and hard work this project would never have existed. We thank also laboratory assistant Birgitta Carell who contributed with tremendous laboratory work. Thanks to all reviewers for their valuable comments, and especially to Andrew L.A. Johnson whose comments helped us to improve the contents and the readability of our paper.

\section{References}

Åkersson A (1993) Luftföroreningar i Skåne. Report for Skånes Luftvårdsförbund published on Internet: http://www.skaneluft. nu/rapport/rapport.htm (in Swedish)

Anonymous (1993) The natural environment in figures. Official statistics of Sweden, 4th edn. Statistics Sweden, p 224

Bøggild OB (1930) The shell structure of molluscs. K Dan Vidensk Selsk SK (Copenhagen) 2:231-325

Carter JG (1980) Guide to bivalve shell microstructures. In: Rhoads DC, Lutz RA (eds) Skeletal growth of aquatic organisms. Plenum Press, NY, pp 645-674

Cook ER, Kairiukstis LA (eds) (1990) Methods of dendrochronology. Applications in the environmental sciences. Kluwer Academic Publishers, Dordrecht, p 394

Dunca E (1999) Bivalve shells as archives for changes in water environment. Vatten 55:279-290

Dunca E, Mutvei H (2001) Comparison of microgrowth pattern in Margaritifera margaritifera shells from south and north Sweden. Am Malacol Bull 16:239-250

Dunca E, Mutvei H, Schöne RB (2005) Freshwater bivalves tell of past climates: but how clearly do shells from polluted rivers speak? Palaeogeogr Palaeoclimat Palaeoecol 228:43-57. doi: 10.1016/j.palaeo.2005.03.050

Göransson P, Karlsson M (1997) Kustkontrollprogram för Helsingborg. Årsrapport 1996. Miljökontoret Helsingborg (in Swedish)

Göransson P, Börjesson L, Karlsson M (2003) Kustkontrollprogram för Helsingborg. Årsrapport 2002. Miljökontoret Helsingborg (in Swedish)

Grossman EL, Ku TL (1986) Oxygen and carbon isotope fractionation in biogenic aragonite; temperature effects. Chem Geol 59:59-74. doi:10.1016/0009-2541(86)90044-6

Hurrell JW (1995) Decadal trends in the North Atlantic Oscillation: regional temperatures and precipitation. Science 269:676-679. doi: $10.1126 /$ science. 269.5224 .676

Hurrell JW, Kushnir Y, Visbeck M (2001) The North Atlantic oscillation. Science 291:603-605. doi:10.1126/science.1058761

Johannesson G (1980) Helsingborg - stad i 900 år. AWE/Geber, Stockholm, p 360 (in Swedish)

Lintrup MJ, Jakobsen F (1998) The importance of Öresund and the Drogden Sill for Baltic inflow. J Mar Syst 18(4):354

Mutvei H (1979) On the internal structures of the nacreous tablets in molluscan shells. Scan Electron Microsc 2:457-462

Mutvei H, Westermark T (2001) How environmental information can be obtained from naiad shells. In: Bauer G, Wächtler K (eds) Ecological Studies 145, Springer, Heidelberg, p 367-379

Mutvei H, Westermark T, Dunca E, Carell B, Forberg S, Bignert A (1994) Methods for the study of environmental changes using the structural and chemical information in molluscan shells. Bull Inst Océanogr 13:163-186

Nyström J, Dunca E, Mutvei H, Lindh U (1996) Environmental History as Reflected by Freshwater Pearl Mussles in the River Vramsån, Southern Sweden. Ambio XXV 5:350-355

Ropes JW, Jones DS, Murawski SA, Serchuk FM, Jearld A (1984) Documentation of annual growth lines in ocean quahogs Arctica islandica Linné. Fish Bull 82(1):1-19

Rühling ̊ (2005) Report: tungmetallnedfall i Skåne. Mätningar år 2005. http://www.skaneluft.nu/rapport/rapport.htm(in Swedish)

Schöne BR, Oschmann W, Rössler J, Freyre-Castro AD, Houk SD, Kröncke I, Dreyer W, Janssen R, Rumohr H, Dunca E (2003) 
North Atlantic oscillation dynamics recorded in shells of a longlived bivalve mollusk. Geol 31:1237-1240. doi:10.1130/ G20013.1

Schöne BR, Dunca E, Fiebig J, Pfeiffer M (2005a) Mutvei's solution: an ideal agent for resolving microgrowth structures of biogenic carbonates. Palaeogeogr Palaeoclimat Palaeoecol 228:149-166. doi:10.1016/j.palaeo.2005.03.054

Schöne BR, Pfeiffer M, Pohlmann T, Siegismund F (2005b) A seasonally resolved sub-sea surface temperature record over $\mathrm{AD}$ 1866-2002 based on shells of bivalve mollusks (Arctica islandica, North Sea). Int J Climatol 25:947-962. doi:10.1002/ joc. 1174

Schöne RB, Dunca E, Mutvei H, Baier S, Fiebing J (2005c) Scandinavian climate since the late 18 th century reconstructed from shells of bivalve molluscs. Z dt Ges Geowiss 156(4):501516
Schöne RB, Fiebig J, Pfeiffer M, Gleß R, Hickson J, Johnson LAA, Dreyer W, Oschmann W (2005d) Climate records from bivalved Methuselah (Arctica islandica, Mollusca; Iceland). Palaeogeogr Palaeoclimat Palaeoecol 228:149-166. doi:10.1016/j.palaeo. 2005.03.054

Thompson I, Jones DS (1977) The ocean quahog, Arctica islandica, "tree" of the North Atlantic shelf. (Abstract) Geol Soc Am 9:1199

Thompson I, Jones DS, Dreibelbis D (1980) Annual internal growth banding and the life history of the ocean quahog, Arctica islandica, (Mollusca, Bivalvia). Mar Biol (Berl) 57:25-34. doi: 10.1007/BF00420964

Westermark T, Carell B, Mutvei H, Forsberg S, Kulakowski E (1996) Elemental content in shells of ocean quahog Arctica islandica $\mathrm{L}$ (Mollusca: Bivalvia) from NW Europe as marine environmental archives. Bull Inst Océanogr 14:105-111 